\title{
Low-dose aspirin as treatment for central serous chorioretinopathy
}

This article was published in the following Dove Press journal:

Clinical Ophthalmology

2 August 2010

Number of times this article has been viewed

\author{
Antonio Caccavale ${ }^{1}$ \\ Filippo Romanazzi' \\ Manuela Imparato' \\ Angelo Negri' \\ Anna Morano ${ }^{2}$ \\ Fabio Ferentini' \\ 'Department of Ophthalmology, \\ Hospital C Cantù, Abbiategrasso, \\ Milan; ${ }^{2}$ University Eye Clinic, \\ Foundation IRCCS San Matteo \\ Hospital, Pavia, Italy
}

Correspondence: Antonio Caccavale Hospital C Cantù, Abbiategrasso, 2008I Milan, Italy

Tel +39029486202

Fax +39029486202

Email neureye@katamail.com
Purpose: To evaluate the effectiveness of low-dose aspirin for the treatment of central serous chorioretinopathy (CSCR).

Patients and methods: Patients with classical or multifocal CSCR were treated with aspirin $100 \mathrm{mg}$ per day orally for 1 month followed by $100 \mathrm{mg}$ on alternate days for 5 months. Treated patients were compared with historic controls consisting of patients with classical or multifocal CSCR previously followed up at our institution.

Results: Mean visual acuity in the group treated with aspirin started to improve after the first week of therapy and continued to improve throughout the following 3 months. Visual recovery was slower in the untreated control group than in the treated group and achieved better visual acuity between the first and third month from the onset of the disease. There were no adverse events related to the administration of aspirin.

Conclusion: The results indicate that treatment with low-dose aspirin may result in more rapid visual rehabilitation with fewer recurrences in patient with CSCR compared with untreated historic controls. The effectiveness of treatment with aspirin supports our hypothesis regarding the role of impaired fibrinolysis and increased platelet aggregation in the choriocapillaris in the pathogenesis of CSCR.

Keywords: central serous chorioretinopathy, aspirin, plasminogen activator inhibitor 1, macula

\section{Introduction}

Central serous chorioretinopathy (CSCR) is characterized by serous detachment of the neurosensory retina due to focal leakage of choroidal interstitial fluid because of a breakdown of the retinal pigment epithelium (RPE). The neurosensory detachment is sometimes associated with a detachment of the RPE. A multifocal variant of CSCR is also recognized. This form is characterized by multiple points of leakage on fluorescein angiography (FA) secondary to widespread decompensation of the RPE and by a chronic course with a less favorable prognosis than classic CSCR.

While the clinical appearance of CSCR is well recognized, less is known about the underlying pathogenetic mechanism of the disease. Dysfunction of the RPE, hyperpermeability of the choroid, and choroidal ischemia have been suggested as the possible primary injury responsible for the disruption of the RPE barrier and consequent neurosensory detachment. Nevertheless, many reports indicate a focal occlusion of the choriocapillary as a cause of the decompensation of the overlying RPE. ${ }^{1-6}$

CSCR is reported to be associated with uncontrolled hypertension and preeclampsia, and is described in patients undergoing hemodialysis. It is classically 
described as affecting middle-aged people, with a male prevalence, and in personality types who exhibit a high stress response. $^{7-11}$

An enhanced response to stress with increased secretion of catecholamines and relative hypercortisolism secondary to hypothalamus-pituitary-adrenal axis stimulation has been reported in patients with CSCR. ${ }^{12-15}$ In addition, bone marrow and solid organ transplantation, ${ }^{16,17}$ vasculitis, ${ }^{18}$ lupus, ${ }^{19}$ inflammatory bowel disease, ${ }^{20,21}$ and Cushing's syndrome ${ }^{22}$ have also been associated with CSCR, as well as exposure to exogenous glucocorticoids. ${ }^{23,24}$

All the factors associated with CSCR have as their common denominator increased hypercoagulability and increased platelet aggregation. Steroids can also induce hypercoagulability and increased platelet aggregation. Increased coagulation and platelet aggregation appear to explain the connection between use of steroids and onset of CSCR through a focal, transitory, or permanent occlusion of the choroidal vasculature. This chain of events appears to be linked to an increase in plasminogen activator inhibitor 1 (PAI-1). A previous study suggested the use of ibuprofen in the treatment of central serous chorioretinopathy, ${ }^{25}$ and others have found elevated PAI-1 in patients with CSCR. ${ }^{26,27}$ Aspirin possesses antiaggregant effects and is effective in reducing serum levels of PAI-1.

Given the evidence of a role for PAI-1 in the pathophysiology of CSCR, we have started to treat patients with CSCR using low-dose aspirin. Our previously reported pilot study has shown that administration of aspirin does appear to influence the course of CSCR. ${ }^{28}$ To define the effectiveness of this new treatment strategy, we performed a study comparing the results obtained in patients treated with aspirin with those in a historic control group consisting of patients with CSCR who were not taking low-dose aspirin.

\section{Material and methods}

We enrolled all patients with active classic or multifocal CSCR referred between January 2005 and February 2009 to the Retina Service of the Department of Ophthalmology, Hospital C Cantù, Abbiategrasso, Milan. Exclusion criteria were other ocular or retinal disease, history of coagulation abnormalities or bleeding diathesis, previous laser retinal photocoagulation, history of ulcerative gastric disease, pregnancy, or allergy to aspirin. Previous medical treatment for CSCR, stopped at least 15 days before enrollment, was not an exclusion criterion.

A complete ophthalmic examination was undertaken at admission in all patients, using FA and optical coherence tomography (OCT). FA and OCT were also performed at 1 week, 1 month, 3 and 6 months, and 1 and 2 years. Best correct visual acuity (BCVA, Snellen and logMar) was determined at every follow-up visit.

All patients were prescribed aspirin $100 \mathrm{mg}$ once daily for the first month and on alternate days for the following 5 months. A full informed consent was obtained from each patient participating in the study. The study was approved by the ethics committee of our institution in conformity with the Declaration of Helsinki.

The prospective case series undergoing treatment (Group A), was compared with an historic control group consisting of patients with either classic or multifocal CSCR identified from the files of the Retina Service from June 2001 to December 2004 (Group B) who fulfilled the same inclusion and exclusion criteria as Group A. Patients in Group B had had complete ocular examinations, including FA and OCT, at the same intervals as Group A. Primary endpoints were BCVA and number of recurrences. Secondary endpoints were variation in leakage points observed on FA and the course of serous detachment on OCT.

The Student's t-test was used to compare BCVA values between groups ( $P$ value $\leq 0.05$ was accepted as statistically significant).

\section{Results}

Demographic data for the patient and control groups are shown in Table 1. Groups A and B were comparable for demographics and disease characteristics. Mean follow-up was $18.44 \pm 9.32$ months for Group A and $18.93 \pm 8.48$ months for Group B $(P=0.702)$. BCVA is illustrated in Table 2 and Figure 1. As shown in Table 2, Group B had a better mean BCVA at the initial visit than Group A (20/31 $\pm 20 / 26$ versus $20 / 39 \pm 20 / 29, P<0.0001$ ), although in the same range (Group A 20/25-20/100 and Group B 20/25-20/100). After 1 week, the difference in BCVA between the groups was still evident and statistically significant (Group A 20/36 \pm 20/31, Group B 20/32 $\pm 20 / 26, P=0.0048)$. This reflects an improve-

Table I Demographic data

\begin{tabular}{llll}
\hline & Group A & Group B & P value \\
\hline Patients (eyes) & $109(\mathrm{II} 3)$ & $89(95)$ & \\
Bilateral disease & 4 & 6 & \\
Multifocal central serous & 7 unilateral & $\mathrm{I}$ unilateral & \\
chorioretinopathy & 2 bilateral & 5 bilateral & \\
Age & $42.19 \pm 8.34$ & $41.90 \pm 6.92$ & 0.793 \\
Gender (M:F) & $87: 22$ & $75: 14$ & \\
Follow-up & $18.44 \pm 9.32$ & $18.93 \pm 8.48$ & 0.702 \\
\hline
\end{tabular}


Table 2 Mean visual acuity at the initial visit and during follow-up

\begin{tabular}{|c|c|c|c|}
\hline \multicolumn{4}{|c|}{ Mean visual acuity (Snellen and LogMar) } \\
\hline Time of follow-up & Group A (range) & Group B (range) & $P$ value \\
\hline \multirow[t]{2}{*}{ Initial visit } & $+0.29 \pm 0.16(+0.1 /+0.7)$ & $+0.19 \pm 0.12(+0.1 /+0.7)$ & $<0.0001$ \\
\hline & $20 / 39 \pm 20 / 29(20 / 25-20 / 100)$ & $20 / 31 \pm 20 / 26(20 / 25-20 / 100)$ & \\
\hline \multirow[t]{2}{*}{ One week } & $+0.25 \pm 0.19(+0.0 /+0.7)$ & $+0.20 \pm 0.12(+0.1 /+0.8)$ & 0.0048 \\
\hline & $20 / 36 \pm 20 / 31(20 / 20-20 / 100)$ & $20 / 32 \pm 20 / 26(20 / 25-20 / / 25)$ & \\
\hline \multirow[t]{2}{*}{ One month } & $+0.14 \pm 0.20(+0.0 /+0.7)$ & $+0.21 \pm 0.11(+0.1 /+0.7)$ & 0.004 \\
\hline & $20 / 28 \pm 20 / 32(20 / 20-20 / 100)$ & $20 / 32 \pm 20 / 26(20 / 25-20 / 100)$ & \\
\hline \multirow[t]{2}{*}{ Three months } & $+0.08 \pm 0.16(+0.0 /+0.6)$ & $+0.13 \pm 0.12(+0.0 /+0.6)$ & 0.010 \\
\hline & $20 / 24 \pm 20 / 26(20 / 20-20 / 80)$ & $20 / 27 \pm 20 / 26(20 / 20-20 / 80)$ & \\
\hline \multirow[t]{2}{*}{ Six months } & $+0.10 \pm 0.17(+0.0 /+0.7)$ & $+0.13 \pm 0.12(+0.0 /+0.7)$ & 0.102 \\
\hline & $20 / 25 \pm 20 / 30(20 / 20-20 / 100)$ & $20 / 27 \pm 20 / 26(20 / 20-20 / 100)$ & \\
\hline \multirow[t]{2}{*}{ One year } & $+0.09 \pm 0.17(+0.0 /+0.6)$ & $+0.16 \pm 0.13(+0.0 /+0.6)$ & 0.008 \\
\hline & $20 / 24 \pm 20 / 30(20 / 20-20 / 80)$ & $20 / 26 \pm 20 / 27(20 / 20-20 / 80)$ & \\
\hline \multirow[t]{2}{*}{ Two years } & $+0.07 \pm 0.13(+0.0 /+0.5)$ & $+0.17 \pm 0.13(+0.0 /+0.6)$ & $<0.000$ I \\
\hline & $20 / 23 \pm 20 / 27(20 / 20-20 / 63)$ & $20 / 30 \pm 20 / 27(20 / 20-20 / 80)$ & \\
\hline
\end{tabular}

ment in visual acuity in Group A and unchanged visual acuity in Group B.

At 1 and 3 months, both groups improved, although the BVCA at 1 month (Group A 20/28 $\pm 20 / 32$, Group B 20/32 $\pm 20 / 26, P=0.004$ ) and 3 months (Group A $20 / 24 \pm$ Group B 20/27 $\pm 20 / 26, P=0.010$ ) was better in Group A than Group B.

Between 1 and 3 months, visual acuity also improved in the untreated group. However, the patients who underwent treatment with aspirin showed a better and faster recovery than controls.

Stabilization of visual acuity in Group A and further improvement in Group B was noted after 6 months, with no significant difference between the groups (Group A 20/25 $\pm 20 / 30$, Group B 20/27 $\pm 20 / 26, P=0.102$ ).

However, at 1 year, BCVA in Group A was better than in Group B (20/24 $\pm 20 / 30$ and 20/26 $\pm 20 / 27$, respectively, $P=0.008)$. At the end of the follow-up period, Group A maintained a better BVCA than Group B (20/23 $\pm 20 / 27$ versus 20/30 $\pm 20 / 27, P<0.0001)$.

As shown in Table 3, 86\% of Group A had no recurrences during follow-up; $6.5 \%$ experienced $1-3$ relapses of disease and $7.5 \%$ showed a persistence of CSCR.

In Group B, 57\% had a resolution of CSCR with no recurrences, 23\% had 1-3 further episodes of CSCR, and 20\% had persistence of disease. The numbers of leakage points

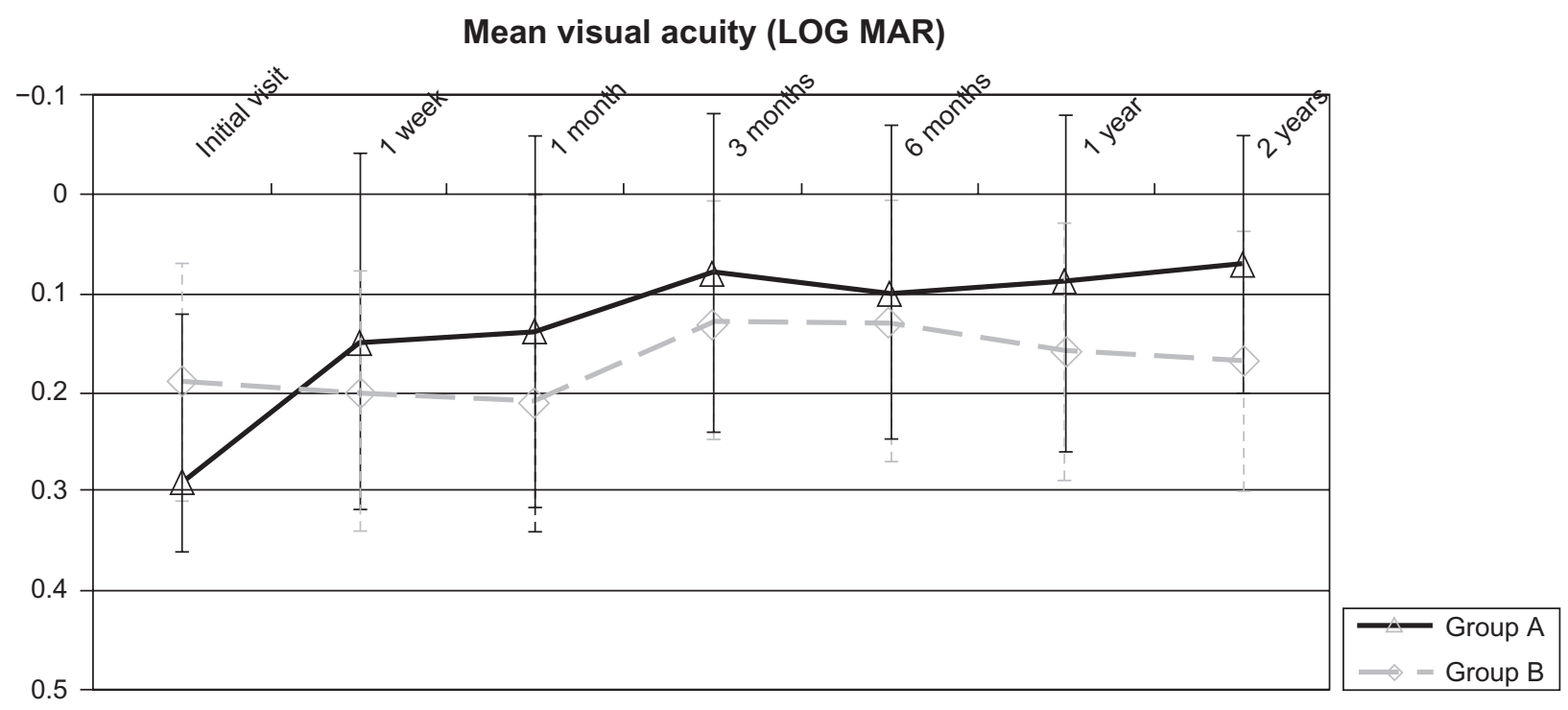

Figure I Trend of mean visual acuity during follow-up. 
Table 3 Number of recurrences in Group A and Group B

\begin{tabular}{lll}
\hline Recurrences & $\begin{array}{l}\text { Patients } \\
\text { Group A (\%) }\end{array}$ & $\begin{array}{l}\text { Patients } \\
\text { Group B (\%) }\end{array}$ \\
\hline 0 & 86 & 57 \\
$\geq I-3$ & 6.5 & 23 \\
Persistence of disease & 7.5 & 20 \\
\hline
\end{tabular}

observed at FA and the course of serous detachment shown at OCT are illustrated in Table 4.

\section{Discussion}

Administration of aspirin enabled a more rapid recovery of the Snellen BCVA and a smaller percentage of recurrences in comparison with the control group. The number of recurrences in the group treated with aspirin was also lower in comparison with previous studies concerning the long follow-up term of CSCR. ${ }^{29-32}$ Patients affected with the multifocal form have shown a limited benefit of therapy, although improvement in visual acuity was found.

None of the patients manifested adverse reactions to aspirin. A gastrointestinal risk exists, but appears to be dose-dependent. Even at low dosage, an increased gastrointestinal risk has been found, ${ }^{33}$ but has been very low $(<3 \%)$, consisting of bleeding ulcers. In our series this did not occur, probably because of the young age of our patients, their lack of history of ulcerative gastric disease, and the total number of patients included being too small to show such a rare complication.

Table 4 Number of leakage points observed at FA and the course of the serous detachment showed at OCT

\begin{tabular}{lll}
\hline FA and OCT & Initial visit \\
\hline $\begin{array}{l}\text { FA leakage } \\
\text { point }\end{array}$ & $\begin{array}{l}\text { End follow-up } \\
\text { (eyes, } \mathbf{n} \text { ) }\end{array}$ \\
\hline Group A & \\
I & 92 & 8 \\
2 & 7 & 2 \\
3 & 3 & 0 \\
$>3$ & 11 & 5 \\
Group B & & \\
I & 70 & 34 \\
2 & 9 & 5 \\
3 & 4 & 2 \\
$>3$ & 12 & 9 \\
Group A & & 15 \\
OCT serous & 113 & \\
detachment & & 50 \\
Group B & & \\
OCT serous & 95 & \\
detachment & &
\end{tabular}

Abbreviations: FA, fluorescein angiography; OCT, optical coherence tomography.
Other treatment options for CSCR are reserved for persistent or chronic forms. Photodynamic therapy with verteporfin was introduced, but its clinical use remains controversial regarding the timing and the fluence of administration. ${ }^{34}$ More recently, intravitreal bevacizumab was suggested for the treatment of classic or chronic CSCR. However, we found only small case reports in the literature with no conclusive clinical outcome. ${ }^{35,36} \mathrm{Lim}$ et al recently showed no positive effect of bevacizumab in classic CSCR patients compared with a control group. ${ }^{37}$ Another pharmacologic approach for treatment of CSCR consists of administration of systemic ketoconazole to decrease endogenous cortisol synthesis, but this has not been associated with an improved outcome in a preliminary study or in a later clinical trial. ${ }^{38,39}$

\section{Conclusion}

The results of this study seem to demonstrate the effectiveness of lower-dose aspirin in the treatment of CSCR but, due to limitations related to use of an historic group as a control, cannot be considered definitive. As demonstration of the self-limited nature of CSCR, we observed a spontaneous improvement of BCVA in the untreated group in the period between 1 and 3 months. Further studies will be needed to be able to individualize the dosage and duration of administration of aspirin and to define better the role of single factors in the coagulative cascade in the onset of this multifactorial illness.

\section{Acknowledgments}

We wish to thank Drs Ralph Levinson and Luciano Prosperi for their support and collaboration in our work, and Dr JL Pecora for his intuition and pioneer investigation of CSCR.

\section{Disclosure}

The authors report no conflicts of interest in this work.

\section{References}

1. Piccolino FC, Borgia L. Central serous chorioretinopathy and indocyanine green angiography. Retina. 1994;14(3):231-242.

2. Prünte C, Flammer J. Choroidal capillary and venous congestion in central serous retinopathy. Am J Ophthalmol. 1996;121(1):26-34.

3. Iida T, Kishi S, Hagimura N, Shimizu K. Persistent and bilateral choroidal vascular abnormalities in central serous chorioretinopathy. Retina. 1999;19(6):508-512.

4. Okushiba U, Takeda M. Study of choroidal vascular lesions in central serous chorioretinopathy using indocyanine green angiography. Nippon Ganka Gakkai Zasshi. 1997;101(1):74-82.

5. Kitaya N, Nagaoka T, Hikichi T, et al. Features of abnormal choroidal circulation in central serous chorioretinopathy. $\mathrm{Br} J$ Ophthalmol. 2003;87(6):709-712

6. Hirami Y, Tsujikawa A, Sasahara M, et al. Alterations of retinal pigment epithelium in central serous chorioretinopathy. Clin Exp Ophthalmol. 2007;35(3):225-230. 
7. Tittl MK, Spaide RF, Wong D, et al. Systemic findings associated with central serous chorioretinopathy. Am J Ophthalmol. 1999;128(1): 63-68.

8. Haimovici R, Koh S, Gagnon DR, et al. Risk factors for central serous chorioretinopathy: A case-control study. Ophthalmology. 2004;111(2): 244-249.

9. Schultz KL, Birnbaum AD, Goldstein DA. Ocular disease in pregnancy. Curr Opin Ophthalmol. 2005;16(5):308-314.

10. Hussain D, Gass JD. Idiopathic central serous chorioretinopathy. Indian J Ophthalmol. 1998;46(3):131-137.

11. Yannuzzi LA. Type-A behavior and central serous chorioretinopathy. Retina. 1987;7(2):111-131.

12. Garg SP, Dada T, Talwar D, Biswas NR. Endogenous cortisol profile in patients with central serous chorioretinopathy. $\mathrm{Br} J$ Ophthalmol. 1997;81(11):962-964.

13. Bouzas EA, Scott MH, Mastorakos G, et al. Central serous chorioretinopathy in endogenous hypercortisolism. Arch Ophthalmol. 1993; 111(9):1229-1233.

14. Haimovici R, Rumelt S, Melby J. Endocrine abnormalities in patients with central serous chorioretinopathy. Ophthalmology. 2003;110(4): 689-703.

15. Tewari HK, Gadia R, Kumar D, et al. Sympathetic-parasympathetic activity and reactivity in central serous chorioretinopathy. Invest Ophth Vis Sci. 2006;47(8):3474-3478.

16. Moon SJ, Mieler WF. Retinal complication of bone marrow and solid organ transplantation. Curr Opin Ophthalmol. 2003;14(6): 433-442.

17. Kian-Ersi F, Taheri S, Akhlaghi MR. Ocular disorders in renal transplant patients. Saudi J Kidney Dis Transpl. 2008;19(5):751-755.

18. Shah VA, Randhawa S, Boldt HC, Lee AG. Central serous chorioretinopathy in giant cell arteritis. Semin Ophthalmol. 2006;21(1):45-48.

19. Cunningham ET Jr, Alfred PR, Irvine AR. Central serous chorioretinopathy in patients with systemic lupus erythematosus. Ophthalmology. 1996;103(12):2081-2090.

20. Kaneko E, Nawano M, Honda N, et al. Ulcerative colitis complicated by idiopathic central serous chorioretinopathy with bullous retinal detachment. Dig Dis Sci. 1985;30(9):896-900.

21. Schreiber JB, Lakhanpal V, Nasrallah SM. Crohn's disease complicated by idiopathic central serous chorioretinopathy with bullous retinal detachment. Dig Dis Sci. 1989;34(1):118-122.

22. Bouzas EA, Scott MH, Mastorakos G, et al. Central serous chorioretinopathy in endogenous hypercortisolism. Arch Ophthalmol. 1993; 111(9):1229-1233.

23. Bouzas EA, Karadimas P, Pournaras CJ. Central serous chorioretinopathy and glucocorticoids. Surv Ophthalmol. 2002;47(5):431-448.
24. Chaine G, Haouat M, Menard-Molcard C, et al. Central serous chorioretinopathy and systemic steroid therapy. J Fr Ophtalmol. 2001; 24(2):217-221. French.

25. Pecora JL. Ibuprofen in the treatment of central serous chorioretinopathy. Ann Ophthalmol. 1978;10(11):1481-1483.

26. Yamada R, Yamada S, Ishii A, Tane S. Evaluation of tissue plasminogen activator and plasminogen activator inhibitor-1 in blood obtained from patients of idiopathic central serous chorioretinopathy. Nippon Ganka Gakkai Zasshi. 1993;97(8):955-960.

27. Iijima H, Iida T, Murayama K, et al. Plasminogen activator inhibitor-1 in central serous chorioretinopathy. Am J Ophthalmol. 1999;127(4): $477-478$.

28. Caccavale A, Imparato M, Romanazzi F, Negri A, et al. A new strategy of tretment with low-dosage acetyl salicylic acid in patients affected by central serous chorioretinopathy. Med Hypotheses. 2009;73(3):435-437.

29. Mitchell GC, Owens SL, Smith PD, Fine SL. Long-term follow-up of central serous chorioretinopathy. Br J Ophthalmol. 1984;68:815-820.

30. Brancato R, Scialdone A, Pece A, et al. Eight-year follow-up of central serous chorioretinopathy with and without laser treatment. Graefes Arch Clin Exp Ophthalmol. 1987;225:166-168.

31. Bujarboua D. Long-term follow up of idiopathic central serous chorioretinopathy without laser. Acta Ophthalmol Scand. 2001;79:417-421.

32. Loo RH, Scott IU, Flynn HW Jr, et al. Factors associated with reduced visual acuity during long-term follow-up of patients with idiopathic central serous chorioretinopathy. Retina. 2002;22:19-24.

33. Sibilia J, Ravaud P, Marck G. Digestive and hemorrhage complications of low-dose aspirin. Presse Med. 2003;32(37 Pt 2):S17-S28.

34. Wang M, Munch IC, Hasler PW, Prünte C, Larsen M. Central serous chorioretinopathy. Acta Ophthalmol. 2008;86(2):126-145.

35. Artunay O, Yuzbasioglu E, Rasier R, Sengul A, Bahcecioglu H. Intravitreal bevacizumab in treatment of idiopathic persistent central serous chorioretinopathy: A prospective, controlled clinical study. Curr Eye Res. 2010;35(2):91-98.

36. Schaal KB, Hoeh AE, Scheuerle A, Schuett F, Dithmar S. Intravitreal bevacizumab for treatment of chronic central serous chorioretinopathy. Eur J Ophthalmol. 2009;19(4):613-617.

37. Lim JW, Ryu SJ, Shin MC. The effect of intravitreal bevacizumab in patients with acute central serous chorioretinopathy. Korean $J$ Ophthalmol. 2010;24(3):155-158.

38. Meyerle CB, Freund KB, Bhatnagar P, Shah V, Yannuzzi LA. Ketoconazole in the treatment of chronic idiopathic central serous chorioretinopathy. Retina. 2007;27(7):943-946.

39. Golshahi A, Klingmüller D, Holz FG, Eter N. Ketoconazole in the treatment of central serous chorioretinopathy: A pilot study. Acta Ophthalmol. 2009 May 12. [Epub ahead of print].
Clinical Ophthalmology

\section{Publish your work in this journal}

Clinical Ophthalmology is an international, peer-reviewed journal covering all subspecialties within ophthalmology. Key topics include: Optometry; Visual science; Pharmacology and drug therapy in eye diseases; Basic Sciences; Primary and Secondary eye care; Patient Safety and Quality of Care Improvements. This journal is indexed on Submit your manuscript here: http://www.dovepress.com/clinical-ophthalmology-journa

\section{Dovepress}

PubMed Central and CAS, and is the official journal of The Society of Clinical Ophthalmology (SCO). The manuscript management system is completely online and includes a very quick and fair peer-review system, which is all easy to use. Visit http://www.dovepress.com/ testimonials.php to read real quotes from published authors. 